\title{
New Solution of vector fuzzy transportation problem in interval integer form
}

\author{
R.Jahirhussain ${ }^{1}$ P.Jayaraman ${ }^{2}$ \\ 1. Associate Professor P.G. \& Research Department of mathematics Jamal Mohamed College Trichy - \\ Tamilnadu -India \\ 2. Research Scholar P.G. \& Research Department of mathematics Jamal Mohamed College Trichy - \\ Tamilnadu -India
}

\begin{abstract}
A vector square fuzzy transportation problem is a special type of transportation problem of the network optimization problems has the special data. Transportation problem with fuzzy supply values of the suppliers and with fuzzy demand values of the receivers. In this paper we are changing in interval form then solving a vector fuzzy transportation problem. A solution concept is attractive from the standpoint of feasibility and efficiency is specified. An investigation of the stability set of parameters corresponding to one $\alpha$ - efficient solution of the ordinary problem - $\alpha$-VTP to a vector fuzzy transportation problem is presented. We used ranking technique for solve trapezoidal fuzzy number. An illustrative example is given.
\end{abstract}

Keywords: Vector fuzzy transportation problem, square Trapezoidal fuzzy numbers, $\alpha$ - efficiency, Optimal solutions, interval number.

\section{Introduction}

In today's highly competitive market, the pressure on organizations to find better ways to create and deliver value to customers become stronger. How and when to send the product to the customers in the quantities. They want in a cost effective manner, become more challenging. Transportation models provide a powerful framework to meet this challenge. They ensure the efficient movement and timely availability of raw materials and finished goods.

The basic transportation problem was originally stated and latter discussed in [8]. A linear programming problem using L-R fuzzy number was given in [15]. An operator theory of parametric programming for general transportation problem was presented by [2]. A fuzzy transportation problem (FTP) is a transportation problem in which the transportation costs, supply and demand quantities are fuzzy quantities. The objective of the fuzzy transportation problem is to determine the shipping schedule that minimizes the total fuzzy transportation cost while satisfying fuzzy supply and fuzzy demand limits to deal quantitatively with imprecise information in making decisions, Bellman and Zadeh [7] introduced the notion of fuzziness. In the literature many researchers $[4,7]$ have developed various algorithms to FTP with equality constraints.

Chanas et al gives a fuzzy approach to solving the transportation problem [5,6]. He gives the concept of optimal solution of the fuzzy transportation problem with fuzzy cost coefficients. ÓhĖIGEARTAIGH, M. introduced an algorithm for solving transportation problem with fuzzy constraints in [12]. He investigates the relationship between the algebraic structures of the optimal solution of the deterministic problem. Sakawa et al described the profit and cost allocation for a production and transportation using fuzzy programming [14]. Jimenez gives the evolutionary algorithm based on a parametric approach to solve the fuzzy solid transportation problem [10]. Kikuchi shows a method that can be used to adjust the values of the variables in transportation problems [11]; the value of the variable is either a row data or derived from a model. The method uses the concept of fuzzy LP in such a way so as to find a set of values that respects the original observed values as much as possible. Ammar studied the fuzzy vector transportation problem with fuzzy numbers [1] and presents the concept that how can we solve the vector fuzzy transportation problem of trapezoidal number. According to Ammar E.E. and A. Kozae there are however several open points for future research in the area of vector fuzzy transportation problems, to be studied. Some of these points of interest are stated in the following:

a) An algorithm is required for solving single-objective transportation problem with fuzzy parameters in the constraint function.

b) Stability of the optimal solution should be investigated for single objective fuzzy transportation.

c) An algorithm is required for solving multi-objective transportation with fuzzy parameters in (i) in the objective functions and (ii) in the constraint function.

d) Stability of the efficient solution should be investigated for fuzzy multi objective fuzzy transportation problems.

e) Computer codes are needed to be constructed to solve the problems recommended above. 
On this base we are solving a vector fuzzy transportation problem of trapezoidal fuzzy numbers by changing in interval integer form. For this we study vector fuzzy transportation problem with fuzzy supply values of the suppliers and with fuzzy demand values of the receivers. We give characterizing of the active solution set of this problem. By use of concept of $\alpha$ - efficiency, we deduce the corresponding usual problem $\alpha$ FVTP of triangular, trapezoidal fuzzy numbers with methods of linear programming and Vogel approximation method and also compare the results of problem.

MATHEMATICAL FORMULATION OF VECTOR FUZZY TRANSPORTATION PROBLEM

$$
\begin{aligned}
& \mathrm{m} n \\
& \operatorname{Min} Z_{k}(x)=\Sigma \quad \sum C^{k}{ }_{i j} x_{i j} \\
& i=1 \quad j=1 \\
& j=1 \\
& \begin{array}{l}
=\sum_{i=1}^{m} X_{i j}=b_{j} \in\left(\tilde{b}_{j}\right) \alpha \quad j=1,2,3, \ldots \ldots . . n \\
\quad X_{i j} \geq 0
\end{array}
\end{aligned}
$$

Where $i=1,2,3, \ldots . . m$ and $j=1,2,3, \ldots . . . n$

$n \quad m$

$\sum a_{i}=\sum b_{j} \forall a_{i} \in\left(\tilde{a}_{i}\right) \alpha, b_{j} \in\left(\tilde{b}_{j}\right) \alpha$

$j=1 \quad j=1$

The suppliers $\tilde{a}_{i}, i=1,2,3, \ldots \ldots . . m$ (supply) and receivers $\tilde{b}_{j}, j=1,2,3, \ldots \ldots . . n$

are fuzzy

numbers characterized by membership functions $\mu_{\mathrm{aij}}\left(\mathrm{a}_{\mathrm{i}}\right)$ and $\mu_{\mathrm{bj}}\left(\mathrm{b}_{\mathrm{j}}\right)$ respectively.

Deterministic of a vector fuzzy transportation problem

For a certain $\alpha \in[0,1]$ the fuzzy vector transportation problem may be consider a deterministic transportation of $\alpha$ - VTP

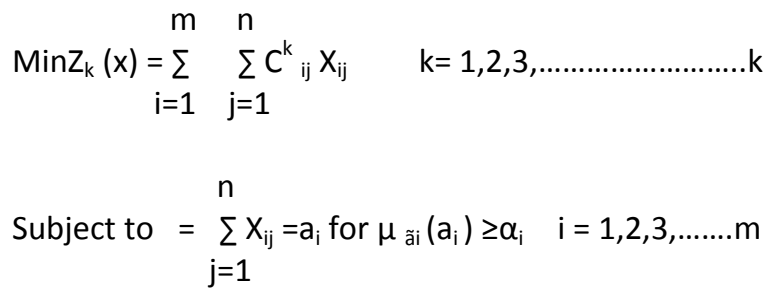

$$
\begin{aligned}
& \sum_{i=1}^{m} X_{i j}=b_{j} \text { for } \mu_{b_{i}}\left(b_{j}\right) \geq \alpha_{j} \quad j=1,2,3, \ldots \ldots . n \\
& \sum_{i=1}^{m} a_{i}=\sum_{j=1} b_{j} \forall a_{i} \in\left(\tilde{a}_{i}\right) \alpha, b_{j} \in\left(\tilde{b}_{j}\right) \alpha \\
& \quad X_{i j} \geq 0 \quad i=1,2,3, \ldots \ldots . . m, j=1,2,3, \ldots \ldots . n
\end{aligned}
$$

\section{Robust Ranking Technique:}

Roubast ranking technique which satisfy compensation, linearity, and additive properties and provides results which are consist human intuition. If a is a fuzzy number then the Roubast Ranking is defined by $\mathrm{R}(\tilde{\mathrm{a}})=\int_{0}^{1} 0.5\left(\mathrm{a}^{\mathrm{L}}{ }_{\alpha} \mathrm{a}^{\mathrm{U}}{ }_{\alpha}\right) \mathrm{d} \alpha$, where $\left(\mathrm{a}^{\mathrm{L}} \mathrm{a}^{\mathrm{U}}{ }_{\alpha}\right)$ is the $\alpha$ level cut of the fuzzy numbers $\mathrm{a}$

Where $\left(\mathrm{a}^{\mathrm{L}}{ }_{\alpha} \mathrm{a}^{\mathrm{U}}{ }_{\alpha}\right)=\{[(\mathrm{b}-\mathrm{a}) \alpha+\mathrm{a}],[\mathrm{d}-(\mathrm{d}-\mathrm{c}) \alpha]\}$ 


\section{Numerical Example:(Trapezoidal Squared fuzzy numbers)}

A company has four sources $S_{1}, S_{2}, S_{3}, S_{4}$ and destinations $D_{1}, D_{2}, D_{3}, D_{4}$. The fuzzy transportation cost for unit quantity of product from $\mathrm{i}^{\text {th }}$ sources $\mathrm{j}^{\text {th }}$ destinations is $\mathrm{C}_{\mathrm{ij}}$

$$
\text { where } C_{i j}=\left[\begin{array}{c}
(1,4,9,16)(4,9,16,25)(9,16,25,36)(16,25,36,49 \\
(4,9,16,25)(9,16,25,36)(16,25,36,49)(25,36,49,64) \\
(9,16,25,36)(16,25,36,49)(25,36,49,64)(36,49,64,81) \\
(16,25,36,49)(25,36,49,64)(36,49,64,81)(25,36,49,81)
\end{array}\right]
$$

Fuzzy availability products at source are (36 4964 81) (16 2536 49 $)$ (4 162536 (25 (25 3649 64) and there Fuzzy demand products and destination are (25 3649 64) (4 16 25 36) (16 253649$)$ (36 4964 81)

\section{Solution:}

The fuzzy Transportation problems are given in Table-1

Table-1

\begin{tabular}{|c|l|l|l|l|l|}
\hline Sources & \multicolumn{1}{|c|}{$\mathrm{D}_{1}$} & \multicolumn{1}{|c|}{$\mathrm{D}_{2}$} & $\mathrm{D}_{3}$ & $\mathrm{D}_{4}$ & $\mathrm{Supply}$ \\
\hline $\mathrm{S}_{1}$ & $(1,4,9,16)$ & $(4,9,16,25)$ & $(9,16,25,36)$ & $(16,25,36,49)$ & $(36496481)$ \\
\hline $\mathrm{S}_{2}$ & $(4,9,16,25)$ & $(9,16,25,36)$ & $(16,25,36,49)$ & $(25,36,49,64)$ & $(16253649)$ \\
\hline $\mathrm{S}_{3}$ & $(9,16,25,36)$ & $(16,25,36,49)$ & $(25,36,49,64)$ & $(36,49,64,81)$ & $(4162536)$ \\
\hline $\mathrm{S}_{4}$ & $(16,25,36,49)$ & $(25,36,49,64)$ & $(36,49,64,81)$ & $(25,36,49,81)$ & $(25364964)$ \\
\hline Demand & $(25364964)$ & $(4,16,25,36)$ & $(16253649)$ & $(36496481)$ & $(81,126,174,230)$ \\
\hline
\end{tabular}

4

here $\sum a_{i}=(81,126,174,230)$

$i=1$

4

here $\sum b_{j}=(81,126,174,230)$

$j=1$

44

$\sum a_{i}=\sum b_{j}$ for each $a_{i} \in\left(\tilde{a}_{i}\right) \alpha$ and $b_{j} \in\left(\tilde{b}_{j}\right) \alpha$

$i=1 \quad j=1$

$$
X_{i j} \geq 0 \quad i=1,2,3, \ldots \ldots . . m, j=1,2,3, \ldots \ldots . n
$$

The vector fuzzy transportation problem in interval integer form

Table-2

\begin{tabular}{|c|l|l|l|l|l|}
\hline Sources & \multicolumn{1}{|c|}{$\mathrm{D}_{1}$} & \multicolumn{1}{|c|}{$\mathrm{D}_{2}$} & \multicolumn{1}{|c|}{$\mathrm{D}_{3}$} & $\mathrm{D}_{4}$ & Supply \\
\hline $\mathrm{S}_{1}$ & $(1,4,9,16)$ & $(4,9,16,25)$ & $(9,16,25,36)$ & $(16,25,36,49)$ & $(36+13 \alpha, 81-17 \alpha)$ \\
\hline $\mathrm{S}_{2}$ & $(4,9,16,25)$ & $(9,16,25,36)$ & $(16,25,36,49)$ & $(25,36,49,64)$ & $(16+9 \alpha, 49-13 \alpha)$ \\
\hline $\mathrm{S}_{3}$ & $(9,16,25,36)$ & $(16,25,36,49)$ & $(25,36,49,64)$ & $(36,49,64,81)$ & $(4+12 \alpha, 36-11 \alpha)$ \\
\hline $\mathrm{S}_{4}$ & $(16,25,36,49)$ & $(25,36,49,64)$ & $(36,49,64,81)$ & $(25,36,49,81)$ & $(25+11 \alpha, 6425 \alpha)$ \\
\hline Demand & $(25+11 \alpha, 64-25 \alpha)$ & $(4+12 \alpha, 36-11 \alpha)$ & $(16+9 \alpha, 49-13 \alpha)$ & $(36+13 \alpha, 81-17 \alpha)$ & $(81+45 \alpha, 230-56 \alpha)$ \\
\hline
\end{tabular}

The above fuzzy interval integer transportation problem is a balanced one. Using separation method [12], now we consider lower bound vector fuzzy transportation problem in integer form is given below:

Table-3

\begin{tabular}{|c|l|l|l|l|l|}
\hline Sources & \multicolumn{1}{|c|}{$\mathrm{D}_{1}$} & \multicolumn{1}{|c|}{$\mathrm{D}_{2}$} & \multicolumn{1}{c|}{$\mathrm{D}_{3}$} & \multicolumn{1}{c|}{$\mathrm{D}_{4}$} & \multicolumn{1}{c|}{ Supply } \\
\hline $\mathrm{S}_{1}$ & $(1,4,9,16)$ & $(4,9,16,25)$ & $(9,16,25,36)$ & $(16,25,36,49)$ & $(36+13 \alpha)$ \\
\hline $\mathrm{S}_{2}$ & $(4,9,16,25)$ & $(9,16,25,36)$ & $(16,25,36,49)$ & $(25,36,49,64)$ & $(16+9 \alpha)$ \\
\hline $\mathrm{S}_{3}$ & $(9,16,25,36)$ & $(16,25,36,49)$ & $(25,36,49,64)$ & $(36,49,64,81)$ & $(4+12 \alpha)$ \\
\hline $\mathrm{S}_{4}$ & $(16,25,36,49)$ & $(25,36,49,64)$ & $(36,49,64,81)$ & $(25,36,49,81)$ & $(25+11 \alpha)$ \\
\hline Demand & $(25+11 \alpha)$ & $(4+12 \alpha)$ & $(16+9 \alpha)$ & $(36+13 \alpha)$ & $(81+45 \alpha)$ \\
\hline
\end{tabular}


Table-4

\begin{tabular}{|c|c|c|c|c|c|}
\hline Sources & $\mathrm{D}_{1}$ & $\mathrm{D}_{2}$ & $\mathrm{D}_{3}$ & $\mathrm{D}_{4}$ & Supply \\
\hline $\mathrm{S}_{1}$ & $(1,4,9,16)(\mathbf{2 1 - \alpha})$ & $(4,9,16,25)$ & $(9,16,25,36)(\mathbf{1 6}+\boldsymbol{\alpha})$ & $\begin{array}{l}(16,25,36,49) \\
\mathbf{1}+\mathbf{5 \alpha})\end{array}$ & $(36+13 \alpha)$ \\
\hline $\mathrm{S}_{2}$ & $(4,9,16,25)$ & $(9,16,25,36)(4+2 \alpha)$ & $(16,25,36,49)$ & $(25,36,49,64)(\mathbf{1 2 - 3 \alpha})$ & $(16+9 \alpha)$ \\
\hline $\mathrm{S}_{4}$ & $(16,25,36,49)$ & $(25,36,49,64)$ & $(36,49,64,81)$ & $\begin{array}{l}(25,36,49,81) \\
(\mathbf{2 5}+\mathbf{1 1 \alpha})\end{array}$ & $(25+11 \alpha)$ \\
\hline Demand & $(25+11 \alpha)$ & $(4+12 \alpha)$ & $(16+9 \alpha)$ & $(36+13 \alpha)$ & $(81+45 \alpha)$ \\
\hline
\end{tabular}

Now the upper bound vector fuzzy transportation problem in integer form is given below:

Table-5

\begin{tabular}{|c|l|l|l|l|l|}
\hline Sources & \multicolumn{1}{|c|}{$\mathrm{D}_{1}$} & \multicolumn{1}{|c|}{$\mathrm{D}_{2}$} & \multicolumn{1}{c|}{$\mathrm{D}_{3}$} & $\mathrm{D}_{4}$ & \multicolumn{1}{c|}{ Supply } \\
\hline $\mathrm{S}_{1}$ & $(1,4,9,16)$ & $(4,9,16,25)$ & $(9,16,25,36)$ & $(16,25,36,49)$ & $(81-17 \alpha)$ \\
\hline $\mathrm{S}_{2}$ & $(4,9,16,25)$ & $(9,16,25,36)$ & $(16,25,36,49)$ & $(25,36,49,64)$ & $(49-13 \alpha)$ \\
\hline $\mathrm{S}_{3}$ & $(9,16,25,36)$ & $(16,25,36,49)$ & $(25,36,49,64)$ & $(36,49,64,81)$ & $(36-11 \alpha)$ \\
\hline $\mathrm{S}_{4}$ & $(16,25,36,49)$ & $(25,36,49,64)$ & $(36,49,64,81)$ & $(25,36,49,81)$ & $(64-25 \alpha)$ \\
\hline Demand & $(64-25 \alpha)$ & $(36-11 \alpha)$ & $(49-13 \alpha)$ & $(81-17 \alpha)$ & $(230-56 \alpha)$ \\
\hline
\end{tabular}

Table-6

\begin{tabular}{|c|c|c|c|c|c|}
\hline Sources & $\mathrm{D}_{1}$ & $\mathrm{D}_{2}$ & $\mathrm{D}_{3}$ & $\mathrm{D}_{4}$ & Supply \\
\hline $\mathrm{S}_{1}$ & $\begin{array}{l}(1,4,9,16)(\mathbf{2 8 -} \\
\mathbf{1 4 \alpha})\end{array}$ & $(4,9,16,25)$ & $\begin{array}{l}(9,16,25,36) \\
\mathbf{1 3 \alpha})\end{array}$ & $\begin{array}{l}(16,25,36,49) \\
(\mathbf{4 + 1 0 \alpha})\end{array}$ & $(81-17 \alpha)$ \\
\hline $\mathrm{S}_{2}$ & $(4,9,16,25)$ & $\begin{array}{l}(9,16,25,36) \\
\mathbf{1 1 \alpha})\end{array}$ & $(16,25,36,49)$ & $(25,36,49,64)(\mathbf{1 3 - 2 \alpha})$ & $(49-13 \alpha)$ \\
\hline $\mathrm{S}_{3}$ & $\begin{array}{l}(9,16,25,36) \\
\mathbf{1 1 \alpha})\end{array}$ & $(16,25,36,49)$ & $(25,36,49,64)$ & $(36,49,64,81)$ & $(36-11 \alpha)$ \\
\hline $\mathrm{S}_{4}$ & $(16,25,36,49)$ & $(25,36,49,64)$ & $(36,49,64,81)$ & $\begin{array}{l}(25,36,49,81) \\
\mathbf{2 5 \alpha})\end{array}$ & $(64-25 \alpha)$ \\
\hline Demand & $(64-25 \alpha)$ & $(36-11 \alpha)$ & $(49-13 \alpha)$ & $(81-17 \alpha)$ & $(230-56 \alpha)$ \\
\hline
\end{tabular}

Now using vogel approximation method, the optimal solution of the upper bound and lower bound fuzzy transportation problem is

$\mathrm{X}_{11}=(21-\alpha) \quad \mathrm{X}_{13}=(16+\alpha) \quad \mathrm{X}_{14}=(-1+5 \alpha) \mathrm{X}_{22}=(4+2 \alpha) \quad \mathrm{X}_{24}=(12-3 \alpha) \quad \mathrm{X}_{31}=(4+12 \alpha) \quad \mathrm{X}_{44}=(25+11 \alpha)$

$\mathrm{Y}_{11}=(28-14 \alpha) \mathrm{Y}_{13}=(49-13 \alpha) \mathrm{Y}_{14}=(4+10 \alpha) \mathrm{Y}_{22}=(36-11 \alpha) \mathrm{Y}_{24}=(13-2 \alpha) \mathrm{Y}_{31}=(36-11 \alpha)$

$\mathrm{Y}_{44}=(64-25 \alpha)$

Thus an fuzzy optimal solution for the vector fuzzy transportation problem is

$[2237.75+1069.25 \alpha, 6413-1797 \alpha]$

\section{Special cases Case 1:}

when $\alpha=0$

The interval cost is $[2237.75,6413]$ And the optimum value of the objective function of the problem is min $(2237.75+6413)=8650.75$

Case 2:

\section{when $\alpha=0.5$}

The interval cost is [2772.38, 5514.5] And the optimum value of the objective function of the problem is min $(2772.38+5514.5)=8286.88$

Case 3:

\section{when $\alpha=0.75$}

The interval cost is [3039.69 ,5065.25] And the optimum value of the objective function of the problem is min $(3039.69+5065.25)=8104.94$

\section{Case 4:}

When $\alpha=1$

The interval cost is $[3307,4611]$ And the optimum value of the objective function of the problem is $\min$ (3307 $+4611)=7923$

\section{Conclusion}

In this paper, we obtained an optimal solution for vector fuzzy transportation with trapezoidal membership functions. The new arithmetic operations of trapezoidal square fuzzy numbers are employed to get the fuzzy optimal solutions. At first we change fuzzy transportation in integer form and solve by vogel approximation method. And also verified in the trapezoidal membership function, which would be a new attempt in solving the transportation problem in fuzzy environment. The same approach for solving the fuzzy problems may also be utilized in future studies in operational research. Also we solve the problem in the sense 
of minimising problem using $\alpha$ - cuts. By trial or error method we get solutions on $\boldsymbol{\alpha}=\mathbf{0}, \mathbf{0 . 5}, \mathbf{0 . 7 5}, \boldsymbol{\&} 1.0$ we get the optimum cost at is $\boldsymbol{\alpha}=\mathbf{7 9 2 3}$

\section{References}

[1]. Ammar E.E. and A. Kozae (2011) "A study on fuzzy vector transportation problem with fuzzy data" journal of nature science and mathematics, vol. 5, no. 1, pp 27-40.

[2]. Balachandran.V, and Thompson.G.L (1975) "An operator theory of parametric programming for the generalized transportation problem I basic theory" Nov. Res.Log. Quart,22,79-100.

[3]. Bellman.R.E, and Zadeh.L.A. (1970) "Decision-making in a fuzzy environment management Science", Journal Vol 17 B141 CB164.

[4]. Charnes.A,and klingman.D. (1977) "The more-for-less paradox in the paradox in the distribution models", cahiers du centre di.Etudes recherché operationnelle, Journal Vol 13 pp 11-32.

[5]. Chanas, S., Kolodziejczk, W. and Machaj A. (1984); "A fuzzy approach to the transportation problem” FSS 13,211-221.

[6]. Chanas, S. Kuchta, D. (1996) "A concept of the optimal solution of the transportation problem with fuzzy cost coefficient" FSS, $82(3)$ pp 299-305

[7]. Chen.S.H. (1985) "Operations on fuzzy numbers with function principle" Tamkang Journal of Management Sciences, Journal Vol 6 pp13-25.

[8]. Hitchock (1978) "Distribution of product from several sources to numerous localities" Journal of Math Physics, Volume 12 No.3.

[9]. R.Jahirhussain ' P.Jayaraman fuzzy optimal transportation problem by improved zero suffix method via robust rank techniques International Journal of Fuzzy Mathematics and Systems (IJFMS). Volume 3 (2013) pp 303-311

[10]. Jiménez F., Verdegay J.L. (1999) "Solving fuzzy solid transportation problems by an evolutionary algorithm based parametric approach" European Journal of Operation Research (117) 3 485-510.

[11]. Kikuchi S. (2000) “A method of defuzzify the number: transportation problem application" FSS 116 (1)pp 3-9.

[12]. ÓhËIGEARTAIGH(1982), M.; A fuzzy transportation algorithm, FSS, 8 pp 235-243.

[13]. Pandian P. and Natrajan G. (2010), "A new method for finding an optimal solution of fully interval integer transportation problem" applied mathematical sciences, $4,1819-1830$.

[14]. Sakawa M. and Nishizaki, Ichiro, Uemura Yoshio (2001) "Fuzzy programming and profit and cost allocation for a production and transportation problem" European Journal of Operation Research (131) 1 pp 1-15.

[15]. Stepan Dlanagar .P, and Palanivel.K., (2009) "On Trapezoidal membership function in solving Transportation problem under fuzzy environment” International Journal of Computational Physical Sciences. Vol (2(3)), pp 93-106.

[16]. Shugani Poonam, Abbas S. H. and Gupta V.K. Solution of vector fuzzy transportation problem in interval integer form International Journal of Mathematical Sciences, Technology and Humanities 55 (2012) 587 - 592 